\title{
Correction to: An loT Service Aggregation Method Based on Dynamic Planning for QoE Restraints
}

\author{
Bing Jia ${ }^{1,2} \cdot$ Lifei Hao $^{1} \cdot$ Chuxuan Zhang ${ }^{1} \cdot$ Huili Zhao $^{3} \cdot$ Khan Muhammad $^{4}$
}

Published online: 22 April 2019

(C) Springer Science+Business Media, LLC, part of Springer Nature 2019

\section{Correction to: Mobile Netw Appl (2019) 24:25-33 https://doi.org/10.1007/s11036-018-1135-7}

The original version of this article unfortunately contained mistakes in the author group and affiliation sections. Author Khan Muhammad's given name and surname were interchanged. His affiliation should also be updated to "Department of Software, Sejong University, Seoul, Republic of Korea".

Publisher's Note Springer Nature remains neutral with regard to jurisdictional claims in published maps and institutional affiliations.

The online version of the original article can be found at https://oi.org/ 10.1007/s11036-018-1135-7

Khan Muhammad

khan.muhammad.sju@gmail.com; khan@sejong.ac.kr

Bing Jia

jiabing@imu.edu.cn

1 Inner Mongolia University, Hohhot, China

2 Inner Mongolia A.R. Key Laboratory of Wireless Networking and Mobile Computing, Inner Mongolia University, Hohhot, China

3 Nankai University, Tianjin, China

4 Department of Software, Sejong University, Seoul, Republic of Korea 